\title{
Tecnologia, corpo e educação física: entre a formação e a prática docente
}

\author{
Technology, body and physical education: between training and teaching practice \\ Tecnología, cuerpo y educación física: entre la formación y la práctica docente \\ EVANDro ANTONio CORRÊA ${ }^{1}$; DeIVIDE TElles DE LIMA ${ }^{2}$ \\ FACULDADES INTEGRADAS DE JAÚ, FIJ, JAÚ-SP, BRASIL
}

\begin{abstract}
RESUMO
Este ensaio visa refletir as relações entre a formação em Educação Física, o corpo em movimento e as tecnologias na educação escolar. Compreendemos que a Educação Física precisa compreender esse corpo e suas diferentes nuances face as tecnologias, as quais podem contribuir como ferramentas auxiliadoras no processo de emancipação dos seres humanos no sentido de se tornarem mais reflexivos, críticos e criativos. Com os avanços das tecnologias observamos mudanças rápidas na sociedade, e o mesmo com o corpo. Torna-se necessário o debate sobre as inter-relações que ocorrem na sociedade entre a tecnologia, corpo e educação como um processo histórico e contínuo de transformações que envolvem questões culturais, econômicas, políticas, sociais que tem (re)configurado a atuação do professor de Educação Física com "novos" saberes e competências no âmbito escolar.
\end{abstract}

Palavras-chave: Educação Física. Corpo. Tecnologia. Educação.

\begin{abstract}
This essay aims to reflect the relationship between training in Physical Education, the body in movement and technologies in school education. We understand that Physical Education needs to understand this body and its different nuances in the face of technologies, which can contribute as auxiliary tools in the emancipation process of human beings in order to become more reflective, critical and creative. With advances in technologies, we observe rapid changes in society, and the same with the body. It is necessary to debate the interrelationships that occur in society between technology, body and education as a historical and continuous process of transformations involving cultural, economic, political, social issues that have (re)configured the role of the Physical Education teacher with "new" knowledge and skills in the school environment.
\end{abstract}

Keywords: Physical Education. Body. Technology. Education.

\section{RESUMEN}

Este ensayo tiene como objetivo reflejar las relaciones entre la formación en Educación Física, el móvil y las tecnologías en la educación escolar. Entendemos que la Educación Física necesita comprender este cuerpo y sus diferentes matices de cara a las tecnologías, que pueden contribuir como herramientas auxiliares en el proceso de emancipación del ser humano para volverse más reflexivo, crítico y creativo. Con los avances de la tecnología observamos cambios rápidos en la sociedad, y lo mismo ocurre con el cuerpo. Es necesario debatir las interrelaciones que se dan en la sociedad entre tecnología, cuerpo y educación como un proceso histórico y continuo de transformaciones que involucran cuestiones culturales, económicas, políticas, sociales que han (re) configurado el rol del docente de Educación Física con "nuevos" saberes, competencias en el entorno escolar.

Palabras clave: Educación Física. Cuerpo. Tecnología. Educación.

\footnotetext{
1 Professor das Faculdades Integradas de Jaú. E-mail: prof.evandrocorrea@gmail.com. ORCID: https://orcid.org/0000-0002-0185-6674.

${ }^{2}$ Professor das Faculdades Integradas de Jaú. E-mail: deivide tl@ hotmail.com. ORCID: https://orcid.org/0000$\underline{0002-2317-0948}$
} 


\section{INTRODUÇÃO}

$\mathrm{Na}$ atualidade observa-se uma explosão de tecnologias em diferentes setores da sociedade, as quais estão em processo contínuo de (re)criação/invenção, desenvolvimento e ampliação e que podem contribuir para as (re)configurações das relações sociais. Em um cenário de transformações na sociedade e dos indivíduos, pensar sobre as questões relacionadas ao corpo, tecnologias e educação tornou-se um desafio, em especial na escola e para os professores de Educação Física Escolar.

Assim, a partir de reflexões sobre as possibilidades de atuação docente, este ensaio, visa apresentar uma discussão referente às relações entre a formação em Educação Física, o corpo em movimento e as tecnologias na educação escolar.

Para Oliveira, Damiano e Pereira (2015), o contexto tecnológico pode estar impondo uma nova identidade ao corpo mediante a diversidade de estímulos virtuais que estabelecem uma inter-relação entre a corporeidade e as interfaces tecnológicas na educação. Para esses autores, algumas conceituações como: "corpo-interator", "multifacetado", "corpo-vibrátil", "corpo-sensível", "corpo virtual" trazem para o debate uma concepção de corpo marcado pela interatividade e por novas possibilidades corporais, permitindo observar como a tecnologia tem ressignificado questões ligadas ao corpo e à educação.

Nesse sentido, as discussões sobre as práticas pedagógicas deveriam considerar a caracterização dos períodos históricos gerada sobre as concepções e funções da Educação Física, corpo e a tecnologia, evidenciando a pluralidade de interpretações e a reinterpretação do papel dos professores em relação ao corpo em movimento.

Com objetivo de superar velhas dicotomias e avançar os olhares em relação ao corpo no contexto escolar, Lima e Hunger (2019) discutem a perspectiva da educação do corpo em movimento. Os autores afirmam que as práticas pedagógicas na Educação Física Escolar devem possibilitar às crianças "[...] expressar-se, movimentar-se, identificar, reconhecer-se, relacionar, conhecer, perceber, em suas ações e nas relações que estabelecem com o mundo e com o outro", por intermédio do corpo em movimento (LIMA; HUNGER, 2019, p. 185).

Percebe-se que apesar da transformação a que os seres humanos estão submetidos, “[...] enquanto membros de uma sociedade informatizada e modernizada, poucos são os que percebem que as atuações profissionais precisam atender aos avanços a que a humanidade se propôs dar" (MACHADO; ZANETTI; MOIOLI, 2011, p. 736).

Mas segundo Harari (2016, p. 7) “[...] o que será que nos espera hoje?”, e vamos adiante, o que nos espera amanhã? Tendo em vista as mudanças ocorridas nas últimas décadas referentes aos recursos tecnológicos para e na Educação. E, principalmente, no último ano (2020-2021) frente a novas "configurações" (ELIAS, 1980) impostas pelo distanciamento social em diferentes contextos incluindo o educacional, com o ensino remoto, híbrido, metodologias ativas etc.

Ao refletir sobre as inserções, interferências e contribuições tecnológicas na vida do ser humano, no corpo, seria possível adquirir, segundo Harari $(2016$, p. 48) " [...] a força de Hércules, a sensualidade de Afrodite, a sabedoria de Atena ou a loucura de Dioniso, se esse fosse o seu desejo. Até agora, aumentar o poder do homem consistiu principalmente em aprimorar suas ferramentas externas". Acredita-se que esses e outros fatores já fazem parte do contexto social dado, por exemplo, ao avanço da "[...] engenharia biológica, engenharia cibernética e engenharia de seres não orgânicos" (HARARI, 2016, p. 48).

Para Carr (2011, p. 68) “[...] toda tecnologia é uma expressão da vontade humana. Através de nossas ferramentas, procuramos expandir o nosso poder e controle sobre as 
circunstâncias - sobre a natureza, sobre o tempo e a distância, sobre o outro". Ao trazer uma breve classificação, grosso modo, Carr menciona que as tecnologias estendem a nossa força física, destreza ou resiliência (inclui o arado, a agulha de costura e o caça a jato); estende a faixa ou sensibilidade dos nossos sentidos (inclui microscópio, amplificador, o contador Geiger - detector de radiação), permitem-nos remodelar a natureza para servir melhor a nossas necessidades ou desejos (abarca tecnologias como o reservatório, pílula anticoncepcional e o milho geneticamente modificado); e, as tecnologias intelectuais (inclui o mapa e o relógio) e todas as ferramentas usadas para estender ou dar suporte aos nossos poderes mentais.

Todavia, Carr (2011, p. 72) alerta ao mencionar a visão determinista e a instrumentalista. $\mathrm{Na}$ visão determinista o "[...] nosso papel essencial é produzir ferramentas cada vez mais sofisticadas - 'fecundar' máquinas como abelhas fecundam plantas -, até a tecnologia desenvolver a capacidade de reproduzir por conta própria. Nesse ponto, tornamo-nos dispensáveis". No outro extremo, temos a visão instrumentalista, em que as pessoas "[...] minimizam o poder da tecnologia, acreditando que as ferramentas são artefatos neutros, inteiramente submersíveis aos desejos conscientes dos seus usuários. Os instrumentos são meios que usamos para alcançar os nossos fins, eles não tem fins em si mesmos".

Seja qual for a ótica, torna-se necessário o debate das inter-relações estabelecidas na sociedade entre a tecnologia, corpo e educação como um processo contínuo de transformações que envolvem questões culturais, econômicas, políticas, sociais. Da mesma maneira, é preciso se atentar para que a tecnologia não amplifique, ainda mais, o distanciamento/abismo socioeconômico entre os seres humanos, não se restringindo a uma elite ou pequena parte da população, como forma de alienação e manutenção do status quo, gerado pela hegemonia do sistema vigente.

Porém, antes mesmo de se pensar nas implicações das "novas" tecnologias referentes ao corpo no ambiente escolar, é preciso observar que alguns limites em relação à ideia de corpo ainda persistem no espaço escolar. Um desses limites é superar as dualidades ainda presentes como a separação corpo e mente no contexto escolar. Esse dualismo, além de fragmentar o corpo-aluno como entidades dissociadas, reforçam falsas dicotomias nos ambientes de aprendizagem, como exemplo, a divisão entre sala e quadra, em que na sala se aprende as questões cognitivas e na quadra ocorre apenas o desenvolvimento físico.

\section{EdUCAÇÃo FíSICA, EdUCAÇÃo, CORPO E TECNOLOGIA: RELAÇÕES E POSSIBILIDADES}

Com o advento da pandemia - COVID-19 -, os professores tiveram que se reinventar e muitos não estavam preparados para desenvolver e executar um trabalho com a utilização de tecnologias, seja pela formação inicial e continuada, ou seja, pela prática docente com a falta de infraestrutura, entre outros obstáculos. E esse processo de aulas remotas, ensino a distância, híbrido etc. em muitos casos e momentos se tornaram um "remendo" no processo educacional e de ensino e aprendizagem. Ou seja, ficou um vácuo nas relações interdependentes entre os professores(as) e alunos(as), alunos(as) e alunos(as), além de outras possíveis configurações educacionais, positivas ou negativas, que somente o tempo e as pesquisas poderão dizer.

Ao fazer um breve resgate sobre a formação em Educação Física, no Brasil, observamos indícios para uma compreensão restrita de corpo, pois trata-se de um corpo "anatomofisiológico" (SOARES, 2007, p. 50). A Educação Física que compreendemos hoje, desenvolveu-se a partir de sua institucionalização na escola, e sob influências 
médica e militar, definindo a forma como o corpo deveria ser abordado e entendido. Da mesma maneira, houve influência das escolas europeias (métodos ginásticos, por exemplo, francês, inglês, sueco...) que induziram a formação dos professores de Educação Física, fortalecendo as práticas do pensamento positivista e da ordem médicomilitar.

$\mathrm{Na}$ Europa do século XIX, os métodos ginásticos, surgem em um contexto de revoluções burguesas, industriais, científicas e pedagógicas, fato que exigiu um novo modo de compreender o corpo na Educação Física. As práticas corporais desse período compreendiam o corpo "[...] a partir dos grupamentos musculares e de seu funcionamento orgânico, fazendo prevalecer uma educação do corpo e do movimento para a utilidade gestual fabril" (NÓBREGA et al., 2018, p. 118).

Dessa forma, no Brasil nos primórdios da Educação Física, fica evidente que a questão do corpo foi vista como um meio para auxiliar no alcance de alguns objetivos específicos como, "[...] para cumprir a função de colaborar na construção de corpos saudáveis e dóceis para o trabalho" (BRACHT, 1999, p. 73), legitimado pelo conhecimento médico-científico do corpo que referendava a necessidade e as vantagens de tal intervenção sobre o corpo.

Hunger et al. (2009) apontam que até a primeira metade da década de 1980, preocupava-se com "[...] ensino e transmissão dos fundamentos, técnicas e táticas dos chamados esportes tradicionais" (p. 80). Nesse período, em relação à formação em Educação Física, os autores relataram que as produções científicas a respeito do movimento humano eram "[...] majoritariamente de natureza biológica. [...] acreditandose que assim seria estabelecido o 'status' científico da Educação Física" (HUNGER et al., 2009, p. 81).

Nesse sentido, a formação dos professores em Educação Física carrega uma vertente mecanicista, com uma "[...] orientação semelhante à da biologia e da ciência médica (cartesiana) em que o organismo - 'o corpo' - tem sido estudado por partes, de forma isolada e não como uma expressão cultural” (HUNGER et al., 2009, p. 83). Para esses autores, uma pesquisa com alunos de graduação mostrou que o campo da Educação Física traz ainda uma visão positivista de ciência, sem ainda conseguir "[...] superar a hegemonia do conhecimento 'biologicista' e do conhecimento "dicotomizado"' (HUNGER et al., 2009, p. 90).

Nóbrega (2005, p. 53) apresenta como hipótese desse problema, a perspectiva cartesiana de corpo, que resultou no "corpo-máquina", instaurando o "dualismo entre corpo versus mente". Para autora, a Educação Física deve superar a ideia mecanicista que instrumentaliza o corpo, para uma visão do corpo-sujeito, "sensível, transversalizado pela percepção do movimento".

Por sua vez, ao longo da formação do profissional atuante na área da Motricidade Humana, para Schwartz (2019, p. 217) raramente "[...] recebe alguma informação específica, ou é colocado em uma situação reflexiva acerca das novas formas de se movimentar, para introduzir as especificidades exigidas na atualidade". Todavia, é preciso atentar para as Instituiçõoes de Ensino Superior (IES) ou para cursos de formação em que "[...] ainda não são oferecidas disciplinas, nem mesmo conteúdos específicos para discussão sobre esses assuntos, levando em consideração essas relações do corpo com o ambiente virtual" (SCHWARTZ, 2019, p. 217) e com outras tecnologias no contexto educacional e da Educação Física.

Há, no entanto, esforços que visam compreender a totalidade do corpo na educação. Sergio (1996) mostra que a expressão "Educação Física" é fruto de um dualismo antropológico racionalista. Apresenta uma perspectiva importante sobre a ideia de corpo e movimento com a Ciência da Motricidade Humana, sendo essa "[...] 
indiscutivelmente uma ciência humana e social, ao lado da história" que deve estar atenta a três pontos: "compreensão das pessoas", "compreensão da sociedade" e a "compreensão da dinâmica da vida social" (SERGIO, 2010, p. 115).

Assim, a Ciência da Motricidade Humana representa um "[...] salto qualitativo, em relação ao dualismo e mecanicismo, racionalistas" e, também, o "[...] alargamento e aprofundamento de um campo profissional” (SERGIO, 2010, p. 116-119).

Nessa mesma direção, Gonçalves Júnior (2009, p. 701) destaca a motricidade como "[...] movimento intencional de transcendência, portanto, do ser no contexto do mundo". Assim, "[...] na perspectiva da motricidade humana entendemos o ser de modo integral existindo-aí-no-mundo-com-os-outros, em condição de abertura para a experiência e, nessa abertura, não há possibilidade de fragmentação" (GONÇALVES JÚNIOR, 2009, p. 701).

Posto isso, na área da Educação Física Escolar, concepções alicerçadas principalmente na fenomenologia da percepção, de Merleau-Ponty, apontam para superação da visão dicotômica de corpo para uma perspectiva de corporeidade. Para o filósofo, o homem não tem um corpo, ele é um corpo, uma experiência vivida do ser (MERLEAU-PONTY, 2006).

Baseados na concepção merleau-pontyana de corpo sensível mediado pela ação da consciência, estudos como Moreira e Nóbrega (2008) buscam superar a ideia mecanicista de corpo-objeto, avançando para corpo sujeito, que observa a consciência do movimento. Essas perspectivas abrangentes em relação ao corpo em movimento inspiraram esforços de rompimento com as concepções mecanicistas e dicotômicas que instrumentalizam a ideia do corpo especialmente no âmbito escolar. Encontra-se no campo da Educação Física Escolar perspectivas que buscam olhar o corpo-aluno em sua totalidade, ou seja, considerando um cenário de relações mediadas pela tecnologia, sendo possível pensar nas possibilidades nas interfaces do "[...] corpo em movimento síntese das múltiplas determinações" (LIMA; HUNGER, 2019, p. 57).

É fato que as tecnologias e, principalmente, as mídias sociais afetaram o cotidiano das pessoas em relação ao ideal de corpo. Contudo, nas últimas décadas muitas discussões relativas à tecnologia adentraram no contexto educacional, trazendo para o debate as questões relacionadas ao corpo mediante as novas tecnologias e os processos de ensino e de aprendizagem, em especial na Educação Física.

Na Educação Física as tecnologias sempre fizeram parte de sua constituição, no entanto, a realidade está repleta de desigualdades e injustiças, em que o desafio não está na tecnologia, mas no uso que se faz dela, pautado numa abordagem que fomente a construção de uma sociedade emancipada, de escolhas. Tal realidade permite a reflexão docente e discente sobre estar apto a agir em uma sociedade cada vez mais complexa, sobre o desenvolvimento do ser emancipado política e humanamente, bem como sobre a inclusão/participação na sociedade do conhecimento, com situações reais de alfabetização e letramento tecnológico.

Para Nunes (2007, p. 31) independentemente das diversas interrogações "[...] sobre o que é e o que não é conhecimento, é indiscutível a centralidade da ciência e da tecnologia e o modo como elas transformam profundamente o mundo em que vivemos, ao ponto de se hoje praticamente impossível conceber o mundo sem elas".

Segundo Gaya (2005, p. 324) os “[...] corpos comunicam em seus movimentos a emoção, o sentimento, a afetividade: na dança, no desporto, no jogo e no circo. Somos seres humanos, sujeitos criadores de cultura nos mais diversos domínios de nossa expressão". O autor coloca que para o "[...] professor de educação física e cientista do desporto, interessa-me sobremaneira tratar do domínio relacionado à expressão corporal" e, ainda, a "manifestação de um corpo existencial" (GAYA, 2005, p. 326). 
Corrêa e Hunger (2020a) buscam compreender a partir da teoria eliasiana, as configurações e os cenários de um processo de "tecnização" educacional e da Educação Física Escolar, para além dos impulsos tecnológicos e dos modismos nas práticas pedagógicas. Para esses autores, as relações tecnológicas dentro do contexto escolar podem remodelar as interações dos indivíduos no processo educacional.

$\mathrm{Na}$ Educação Física Escolar, observa-se certa problemática entre os professores (favoráveis e contrários) nas discussões sobre o corpo, o movimento e suas relações com as tecnologias virtuais, a inteligência artificial, ensino remoto e híbrido, educação a distância, uso de aparatos/ferramentas (celular, tablet, computador...), aplicativos, aparelhos de ginástica/musculação independentes e robotizados, os diversos materiais e equipamentos que são processos advindos do desenvolvimento tecnológico, entre uma gama de possibilidades propiciado pela tecnologia. Por um lado, alguns apresentam entusiasmo e avistam novas possibilidades, por outro, há professores que se mostram inseguros, receosos, insatisfeitos e apresentam limitações e problemas em relação às práticas pedagógicas, não entendendo ao certo o que fazer frente às tecnologias e às novas relações que se configuram no espaço escolar.

Assim, seja sonho ou pesadelo, devemos atentar, segundo Corrêa e Hunger (2020b, p. 19), para a inserção da tecnologia na formação em Educação Física. Essa possibilidade pode ser "[...] como conteúdo diluído de forma transversal na matriz curricular ou como disciplina própria que aborde a temática, na preparação desse profissional, de forma coerente e responsável, sem cair nas armadilhas das modernidades passageiras". Portanto, esse debate se faz necessário na formação inicial e, também, continuada em Educação Física pelas IES, a fim de garantir minimamente conhecimentos, habilidades e competências para subsidiar o professor em sua intervenção na escola.

No âmbito das produções científicas em relação ao corpo, estudos como: Corrêa e Hunger (2020a); Uebe e Damiano (2015); Garcia (2010); Le Breton (2007); aprofundam as questões relativas à ideia de corpo na educação e os desafios frente às demandas da sociedade tecnológica e midiática.

$\mathrm{Na}$ escola, esse dinamismo social impõe novas perspectivas para se pensar os processos educativos. Emergem indagações sobre sua estrutura física, formação dos professores, conteúdos, interesses por trás das "inovações tecnológicas" etc. Porém cabe questionar: E o corpo? Qual é a concepção e o lugar do corpo na escola e suas relações com a tecnologia?

Bocchi (2021, p. 84) também contribui em nossas reflexões ao relatar que "[...] interessa tomar o corpo como uma categoria da experiência e da intersubjetividade". Contudo, para os educadores que atuam no campo da Educação ou da Saúde o corpo é organismo, motricidade, anatomia etc. "[...] mas ele não é apenas isso, o corpo também é corporeidade. É neste sentido que propomos pensá-lo como uma categoria da experiência intersubjetiva" (BOCCHI, 2021, p. 84).

Nesse ínterim é possível ver "[...] a ampliação dos limites de compreensão sobre o corpo, agora podendo estar também presente virtualmente" (SCHWARTZ, 2019, p. 216). Podemos notar, portanto, que

[...] é notória, exigindo, inclusive, novas concepções para tempo, espaço e construção simbólica da corporeidade, temáticas importantes, as quais representam um grande desafio para serem discutidas no contexto da Motricidade Humana. [...] Este novo modo de pensar a corporeidade aliada à virtualidade, alarga a percepção de corpo para além da presença física tangível (in loco), o que deflagra inúmeras alterações na sociedade (SCHWARTZ, 2019, p. 216). 
De modo geral, mediante aos avanços das tecnologias e da busca por corpos perfeitos, modificados e adaptáveis, Machado, Zanetti e Moioli (2011, p. 728) questionam "[...] o que esperamos do nosso futuro próximo? [...] Seremos, no futuro imediato, apenas sofisticados e adaptáveis avatares? Ciborgs? Robôs? [...] Teremos corpos híbridos entre o biológico e o artificial ou entre a máquina e a humanidade?".

Sem a intenção de responder a tais indagações, Gaya (2005, p. 324) coloca que "[...] ao longo da história, homens e mulheres têm produzido conhecimentos e técnicas visando atender seus interesses e necessidades". Essa produção talvez conduza o ser humano a ter uma "obsolência do corpo humano"? (GAYA, 2005, p. 326).

Contudo, com as revoluções geradoras da modernidade, a revolução tecnocientífica no século XVI-XVII, a revolução iluminista no século XVIII e a revolução industrial que ganha força no século XIX, possivelmente ditaram uma aceleração dos tempos, permanecendo na contemporaneidade (GAMA, 2013). Apresenta-se que "[...] na esteira de Campbell, consideramos que a revolução industrial foi igualmente foi uma 'revolução do consumo"' (GAMA, 2013, p. 210).

Essas revoluções atreladas a outros acontecimentos deram um start a uma "[...] mentalidade consumista, primeiramente restrita a algumas classes, como nobres, artistas, e, mais latamente, a população burguesa" (GAMA, 2013, p. 210), a qual permanece até hoje envolvendo as tecnologias, a valorização exacerbada de um corpo "perfeito", se é que o teremos algum dia.

Ou ainda, conforme pontua Schwartz (2019, p. 217) "[...] será que os pressupostos das vivências no ambiente virtual são exatamente opostos aos da Motricidade Humana?". A autora também questiona "[...] como o Profissional da área de Motricidade Humana pode se apropriar dos recursos da internet e do ambiente virtual para atualizar e dinamizar suas ações?" (SCHWARTZ 2019, p. 217), e acrescentamos nessas indagações outras tecnologias para além do virtual que podem contribuir para sua intervenção docente.

Para Baldanza (2006) sob a ótica das novas tecnologias de comunicação e informação, pensar no corpo como visto há séculos seria imprudente ou até mesmo irreal. A autora coloca que com o surgimento das tecnologias possibilitaram a comunicação à distância, desde a escrita até mais recentemente a internet, emergindo novas formas de sociabilidade, ou seja, não é necessário estar face a face para interagir com outras pessoas. Por sua vez, significa "[...] dizer que a representação do corpo e suas significações também se alteram, quando se trata deste novo espaço" (BALDANZA, 2006, p. 1).

Mediado pela tecnologia estes novos espaços podem representar, o que em outro tempo e com outros objetivos, a '[...] passagem das antigas 'lojas de novidades' para os grandes armazéns pressupõe alterações significativas que assentam acima de tudo na exposição, nas vitrinas e nas montras para a venda de mercadorias, sobretudo para uma burguesia endinheirada" (GAMA, 2013, p. 212).

Atualmente, não somente a burguesia, da mesma forma com o ocorrido no século XIX, pode-se dizer que as tecnologias e as novas formas de comunicação, principalmente, a internet, segundo Gama (2013, p. 212), "[...] incitam uma nova rotina, uma nova experiência, que se materializava no ato de comprar, surgindo assim uma nova práxis social" além da "[...] gênese e desenvolvimento do novo paradigma do consumo". Consumo esse de tecnologias ou de pacotes tecnológicos educacionais que podem estar presentes na formação inicial e continuada em Educação Física e na escola sem nenhum questionamento e ponderação, o que pode levar a uma situação instrumentalista e de alienação. 
Sobre esse assunto, Selwyn (2017, p. 85) diz que "[...] a tecnologia educacional é agora um negócio multibilionário que envolve corporações globais em nível de práticas e provisão locais. A necessidade de se questionar criticamente a Educação e a Tecnologia é mais premente do que nunca".

Para Baracho, Gripp e Lima (2012, p. 111) o “[...] cenário sociotécnico contemporâneo evidencia as telas digitais como referências de produção, consumo, comunicação, lazer, entre outras". Mencionam, ainda, que esses fatores indicam que "[...] vivemos num tempo em que a sociedade vem se apropriando das funcionalidades das tecnologias digitais de informação e comunicação, e incorporando-as em suas formas de relacionamento" (BARACHO; GRIPP; LIMA, 2012, p. 111).

Ao refletir sobre isso, devemos compreender as novas experiências e contextos como, "ciberespaço"” e "cibercultura" (LÉVY, 1999), "mundo virtual" (LÉVY, 1998), "sociedade digital", "era da informação" e "sociedade em rede" (CASTELLS, 1999) e várias outras terminologias utilizadas para explicar a "nova" realidade, da sociedade contemporânea, mediada pelas diferentes tecnologias, a exemplo, as redes sociais como meio de comunicação.

Assim, com o desenvolvimento e o avanço tecnológico, o aparecimento de modernos meios de telecomunicações tem reconfigurado as atuais formas de espaço e tempo, conduzindo-nos a constantes e rápidas transformações nas formas de representação sobre nós mesmos, sobre as formas de trabalho e sobre a maneira como se concebem e constroem as inter-relações humanas. Tal avanço também está interligado com os modismos emergidos dos "novos" produtos tecnológicos.

Mesmo atrelado à moda, Gama (2013, p. 213) menciona que "[...] nunca como nesta década, o culto da juventude alcançara com tanta abrangência a sociedade. A moda perdia o cariz elitista de outros tempos rumo a democratização e transformava-se num fenômeno de massas". Esse fenômeno pode ser observado na sociedade contemporânea influenciada diretamente pelos recursos tecnológicos disponíveis (internet, computares, celulares, tablet etc.).

Paralelamente, o corpo que também (visto como) é moda, passou e passa por modismos. Machado, Zanetti e Moioli (2011, p. 729) colocam, por exemplo, ao falarem sobre o corpo como arte, que "[...] diferentes formas de se modificar e se marcar fazem com que os corpos humanos estejam em constante transformação e manipulação". Essa ideia "[...] sempre perseguiu o homem, que busca criar e recriar sobre o corpo, num ato para imortalizar sua mensagem e sua fala" (MACHADO, ZANETTI; MOIOLI, 2011, p. 729) e talvez isso se materialize no mundo virtual, dando ao ser humano a imortalidade.

Nesse ínterim, a notícia e a imagem vendem muito, onde "[...] curiosidade, perversão e masoquismo se excitam para 'possuir', para gravar a imagem dos pedaços de carne" (MACHADO; ZANETTI; MOIOLI, 2011, p. 730), sem atentar para o personagem que habitava aquele corpo, além da valorização excessiva ao corpo, quando observamos as propagandas de produtos entregues ao consumismo. Há a "[...] valorização de um corpo rejuvenescido, reeducado por meio de dietas, exercícios, suplementos vitamínicos e dietas da moda, cirurgias plásticas, implantes de silicone e modelagem" (MACHADO, ZANETTI; MOIOLI, 2011, p. 730).

\footnotetext{
${ }^{3}$ Ciberespaço, “[...] é um meio de comunicação que surge da interconexão mundial dos computadores. O termo especifica não apenas a infraestrutura material da comunicação digital, mas também o universo oceânico de informações que ela abriga, assim como os seres humanos que navegam e alimentam esse universo" (LÉVY, 1999, p. 17).

${ }^{4}$ Cibercultura, "[...] o conjunto de técnicas (materiais e intelectuais), de práticas, de atitudes, de modos de pensamento e de valores que se desenvolvem juntamente com o crescimento do ciberespaço" (LÉVY, 1999, p. 17).
} 
Esses fatores poderiam ir ao encontro do que afirma Gama (2013), no qual nos sentimos singulares, sentimo-nos num conto das "Mil e uma Noites", fazendo uma relação às Maisons luxuosas [novas hiper catedrais de consumo com dimensões estratosféricas, ou seja, conglomerados de luxo como Grupo francês Moet Hennessy \& Louis Vuitton (LVMH), o Grupo francês Kering e o Grupo suíço Richemont].

As "[...] imagens são muito fortes e no contexto midiático imprimem uma força e ritmo próprios da construção cultural a que se está pretendendo" (MACHADO; ZANETTI; MOIOLI, 2011, p. 730). Portanto, para Gama (2013) tal atmosfera está embebida de fragrâncias invulgares; a música devidamente escolhida para o espaço da marca que representa; as obras de arte dispostas em espaços milimetricamente estudados. Espaços estes que se tornam inebriantes, cenários que convidam ao sonho, provocam o olhar, onde são convocados todos os sentidos e uma série de artifícios, de modo a suscitar emoções e a fomentar a compra.

Essa embriaguez se torna cada vez mais presente no mundo virtual, com o estreitamento na relação homem-máquina, onde "[...] o ciberespaço cria condições para uma nova forma de sociabilidade, um pouco diferente da sociabilidade habitual caracterizada pela presença física, mas que por vezes, é carregada de emoções, pois é realizada por pessoas reais" (BALDANZA, 2006, p. 4).

Considerando estes aspectos, sob a ótica tecnológica, a Educação Física estaria participando da "cibercultura" e criando em seu interior um "ciberespaço" com suas diversas possibilidades, com a utilização de diferentes recursos (softwares, internet, aplicativos, jogos eletrônicos, entre outros) e equipamentos tecnológicos na construção de corpos? Quais influências externas estariam alimentando o imaginário dos alunos na escola? Como o professor de Educação Física tem lidado com as imagens e construção de corpo em suas aulas? Como os cursos de graduação em Educação Física têm tratado as tecnologias e as relações com o corpo em seus currículos?

Todavia, essas e outras questões devem ser investigadas. E para Corrêa e Hunger (2020b, p. 13):

\footnotetext{
[...] a tecnologia é temática pertinente para formação ou para intervenção profissional, talvez, sem a devida reflexão de como os aparatos tecnológicos contribuem para área. Entendendo que os indivíduos, assim como a tecnologia estão em mutação constante da tecnologia urge a necessidade de debater o papel e a utilização de seus recursos (computadores, telefones celulares, tablets, softwares, jogos eletrônicos, entre outros) na formação do Profissional de Educação Física.
}

Cabe, portanto, fomentar o debate referente ao corpo, educação, Educação Física e tecnologia, compreendendo está última “[...] não como obstáculos às suas práticas, mas com a finalidade de compor parcerias, pesquisar novas possibilidades de treinamentos e aprendizagens, novos usos e auxílio na melhoria dos desempenhos de toda a equipe, inclusive a sua própria" (KENSKI, 1995, p. 133). E que "[...] a tecnologia e a educação são facetas do mesmo desenvolvimento total" (ELIAS, 1993, p. 212). Vale destacar aqui os desafios que ainda há em relação à presença das tecnologias no ambiente escolar e para os alunos como: acesso a rede de internet de qualidade, equipamentos (computadores, celulares, tablet etc.), softwares e aplicativos educacionais, entre outros.

É preciso desafiar todas as hipóteses dessas relações, apresentadas anteriormente, e o aproveitamento do potencial tecnológico com intuito de fornecer possíveis subsídios para melhoria da atuação do professor de Educação Física em suas aulas na escola.

Como observado até o momento, a globalização face à diversidade cultural interfere no amplo uso das tecnologias a fim de melhorar a qualidade de vida do ser humano, uma revisão e/ou quebra de paradigmas, pressupostos e procedimentos ao se 
criar e usar os diferentes recursos tecnológicos e ambientes virtuais. Cabe lembrar que a invenção, apropriação e uso das tecnologias estão presentes desde os primórdios da civilização, com instrumentos rudimentares para caça e pesca, passando pelo fogo, e toda maquinaria inventada pelo ser humano em prol de sua existência.

Para Uebe e Damiano (2015), as interfaces tecnológicas se (inter) relacionam à corporeidade no ambiente educativo, abrindo novas possibilidades para a construção de modos cada vez mais subjetivos de ser e de estar no mundo. O universo tecnológico tem trazido não somente um aumento de produtos softwares e interfaces de hardwares e estudos sobre as Tecnologias da Informação e Comunicação e Inteligência Artificial, mas também, novas formas de se (inter) relacionar e produzir conhecimentos. Novas tecnologias estão reconfigurando as formas de transmissão e assimilação dos conhecimentos e reordenando as relações, a noção de tempo e espaço, modos de ser, pensar e até mesmo as formas de ensinar e aprender (FERREIRA, 2019).

Dessa maneira, “[...] a relação entre corpo, educação e civilização faz suscitar uma série de interrogações, melhor dizendo, de inquietações que podem trazer novos movimentos para pensarmos o homem" (LUCENA, 2017, p. 1320). Conforme destaca Merleau-Ponty (2006, p. 123) é preciso que o “[...] corpo seja apreendido não apenas em uma experiência instantânea, singular, plena, mas ainda sob um aspecto de generalidade e como um ser impessoal". À vista disso, "[...] emissor ou receptor, o corpo produz sentidos continuamente e assim insere o homem, de forma ativa, no interior de dado espaço social e cultural" (LE BRETON, 2007, p. 9).

Ademais, há de se compreender que as "[...] novas tecnologias de comunicação transformam a experiência de corpo: o sentido da presença, a definição do próximo e do longínquo no espaço e no tempo, a distinção entre o real e imaginário" (BALDANZA, 2006 , p. 5). De acordo com a autora o "[...] corpo virtual não se opõe ao real e pouco tem a ver com o falso, o ilusório ou o imaginário. Trata-se sim de um modo favorável e potente de representação do eu e de suas sensações no ciberespaço" (p. 5).

Nesse sentido, Lazzarotti Filho e Figueiredo (2007) chamam a atenção ao se pensar o corpo e sua educação mediada por computador, por exemplo, onde esse assume outros contornos no ciberespaço, sendo um desafio para a Educação Física. Ou ainda, "[...] além de desafiar as fronteiras do tempo e do espaço, o corpo desmaterializado ajuda a ultrapassar outras barreiras no espaço digital" como também a "ausência de um corpo físico nas interações mediadas por computador então favorecem a experimentação de outras identidades ou outros 'eus"” (BALDANZA, 2006).

De acordo com Baldanza (2006) as novas tecnologias reinventam as relações sexuais, a forma do corpo, a experiência de identidade, de comunidade etc. Seria a formação de novo/velho corpo, ou seja, segundo Gaya (2005), a expressão de um homem com as proporções perfeitas no espaço de figuras geométricas perfeitas, o Homem Vitruviano; o corpo investigado, descrito e analisado; o corpo anatômico e biomecânico; a liberação dos códigos convencionais que aprisionam o corpo numa sociedade datada da segunda metade do século XIX; a liberação do corpo; o corpo expressivo; o corpo desprezado, mutilado; corpo mortificado; corpo manipulável pela tecnociência. Desenhado para superar os defeitos do corpo biológico. Um corpo biônico. Uma máquina para onde, em breve, serão transportados os conteúdos da mente. Para autora, teríamos no século XXI a despedida do corpo biológico? Corpos híbridos ente o biológico e o artificial? Seria a morte do corpo humano?

Concordamos com Lucena (2017, p. 1330) ao destacar que devemos compreender “[...] o corpo, como um contínuo que se constrói na interdependência constante do homem com a natureza, do homem com os outros homens, num processo que se renova e possibilita pensarmos na diversidade característica do ser humano". 
Aliás, o corpo e suas representações atravessaram milênios, civilizações e modismos, seria, na sociedade contemporânea, o "[...] corpo da mobilidade, que mesmo virtualmente atravessa fronteiras geográficas, culturais, profissionais, hierárquica, e que é capaz de estabelecer contatos pessoais com diversos e muitas vezes desconhecidos atores", conforme afirma Baldanza (2006, p. 5). Ademais, nesse debate,

Um fato importante que não poderia ocorrer referente a questão do corpo e à
tecnologia é para uma escola imersa na/com a preocupação de controlar os
comportamentos dos alunos, ou seja, um controle de seus corpos em que o
ensino e aprendizagem estariam em privilegiando apenas os elementos
cognitivos e em pacificar o corpo. Assim sendo, na sala de aula, os alunos
deixariam seus corpos e o movimento de forma estática, sob a ótica
pedagógica, dentro do processo de ensino e aprendizagem com o uso das
tecnologias (CORREAA; HUNGER, 2020a, p. 205).

A Educação Física precisa compreender esse corpo e suas diferentes nuances em face à tecnologia. Este corpo está cada vez mais revestido ou vestido por computadores, pela robótica, enfim pela tecnologia e seus recursos. Como exemplo, o uso de próteses por amputados, os exoesqueletos - máquinas que têm como princípio envolvido no seu funcionamento a interface cérebro-máquina. Esta conexão prevê que a "força do pensamento" seja capaz de controlar de maneira direta um equipamento externo ao corpo humano. Outro seria o computador "vestível", que segundo Donati (2004) deve estar incorporado ao espaço pessoal do wearer - usuário, potencializando um uso integrado, sem limitar os movimentos corporais ou impedir a mobilidade do indivíduo. Este tipo de equipamento deve estar sempre ligado e acessível à performance computacional que permite auxiliar o usuário em atividades motoras e/ou cognitivas e não deve ser considerado como uma simples ferramenta.

Portanto, “[...] os saberes construídos sobre o corpo humano são provisórios e contextualizados num dado momento histórico" (PAIVA; GOELLNER, 2008, p. 486). Este corpo e a forma de pensar sobre o mesmo, segundo Abonizio (2011, p. 485), varia entre as sociedades e "[...] na contemporaneidade, o corpo deixa de ser considerado destino e ganha múltiplas possibilidades de remodelação, tanto as que conduzem ao corpo socialmente aceito quanto ao rejeitado pelos valores dominantes".

Com esse quadro apresentado, a relação tecnologia e os profissionais de Educação Física, de acordo com Corrêa e Hunger (2020b, p. 25) "[...] devem apresentar o equilíbrio entre as novas demandas sociais e a necessidade humana, imutável, de interagir com outros seres humanos, ou seja, as relações de interdependência ocasionadas nos processos civilizatório e de tecnização".

O termo "tecnização" é abordado por Norbert Elias (2006), e de acordo com Corrêa e Hunger (2020a, p. 21) ao analisarem a obra de Elias, compreendem a "[...] 'tecnização' como processo que repercute na civilização, atingindo de modo especial as configurações que se estabelecem entre os indivíduos, a sociedade e as tecnologias". Esse processo de "tecnização" também ocorre na Educação e Educação Física e que "[...] pode ampliar as possibilidades de comunicação e interação com o mundo, dos 'conhecimentos sobre o corpo', bem como corroborar com a prática pedagógica docente" (CORRÊA; HUNGER, 2020a, p. 30).

Consequentemente, o exercício da docência com inserção das tecnologias pode emergir de diferentes instâncias, conforme debatido por Tardif (2002), envolvendo os saberes disciplinares, curriculares, profissionais (incluídos os das ciências da educação e da pedagogia) e experienciais. 
Seria possível ir além dessas possibilidades tendo em vista o uso das tecnologias? Quais outros saberes teríamos (ou não) no processo de ensino e aprendizagem nas aulas de Educação Física e o envolvimento das tecnologias?

Corrêa e Hunger (2020a) apresentam alguns encaminhamentos como: saberes ligados ao letramento digital; conhecimento da funcionalidade do recurso tecnológico; o uso da internet e a orientação de pesquisas no ciberespaço; direcionar o aluno de como usar as ferramentas; manusear e usar programas e outros tipos de mídias, entre outras situações que tem despertado novas necessidades e desafios ao professor. Entretanto, alertam para termos cuidado para que o papel do professor não seja reduzido a um mero transmissor de informações (ao invés de formador) para satisfazer às necessidades dos modismos.

Para Nóvoa (2014) “[...] diante de uma mudança de fundo em nossos hábitos e maneiras de viver, o que tem consequências profundas na educação. A relação presencial é fundamental, mas ela pode ser intensificada e enriquecida através dos recursos digitais". E mesmo compreendendo o professor como mediador em sala de aula, frente ao uso das tecnologias "[...] é aquele que tem a expertise e a formação necessária para elaborar, planejar, aplicar e avaliar o conteúdo aplicado aos alunos" (CORRÊA; HUNGER, 2020a, p. 204).

Face ao exposto, professoras e professores, alunas e alunos, gestão escolar, família e comunidades precisam demonstrar abertura para mudanças derivadas das tecnologias em relação ao corpo em movimento no âmbito da Educação Física. Todavia, não deve se render às pressões mercadológicas, modistas e de interesses meramente econômicos ou de uma pequena parcela da sociedade para manter-se no poder. As tecnologias são bem-vindas como ferramentas auxiliadoras no processo de emancipação dos seres humanos para que se tornem cada vez mais reflexivos, críticos e criativos emanados nas/das configurações do corpo consigo mesmos e suas relações interdependentes com outros corpos, tempos e espaços.

\section{CONSIDERAÇÕES FINAIS}

De um modo sintético, pode-se concluir que com avanços das tecnologias observamos mudanças muito rápidas na sociedade, e o mesmo ocorre com o corpo. $\mathrm{O}$ modelo social e econômico vigente afeta diretamente a construção do(s) corpo(s), motivados por uma embriaguez que o espaço, ao ativar todos os sentidos e uma série de artifícios, representa; são milimetricamente estudados, formando cenários reais $\mathrm{e}$ virtuais para assim fomentar o consumo.

Todavia, não é de hoje que o corpo é embelezado, é transformado, no qual a formação do corpo, sua representação e suas significações também se alteram, e na contemporaneidade, quando se trata de um novo espaço. Somente o tempo será capaz de dizer se o corpo será a expressão de um homem com as proporções perfeitas, avatares, ciborgues, anatômico e biomecânico, expressivo, desprezado, modificado, biônico e/ou biológico. Que corpo?

À luz desses apontamentos, convém avançar em futuros estudos e pesquisas tendo em vista a formação (inicial e continuada) em Educação Física e o debate relacionado ao corpo, às tecnologias e à educação, (re)configurando a atuação docente com "novos" saberes, competências e conhecimentos.

Por fim, é relevante compreender as mudanças históricas, como um processo de configurações, da sociedade e a representação do corpo, para que no presente e futuro, as relações com e na Educação e Educação Física possam se apropriar da elaboração e 
formação de saberes necessários para e na articulação com/das tecnologias, sem perder sua essência, a humanidade, na formação de pessoas emancipadas, críticas e criativas.

\section{REFERÊNCIAS}

ABONIZIO, J. Outros olhares sobre os outros - a presença incômoda dos corpos modificados em blogs. Polêm!ca, v. 10, n. 3, p 484-493, jul./set. 2011.

BALDANZA, R. F. Comunicação no ciberespaço: reflexões sobre a relação do corpo na interação e sociabilidade em espaço Virtual. In: CONGRESSO BRASILEIRO DE CIÊNCIAS DA COMUNICAÇÃO, 29., 2006, Brasília. Anais [...]. Brasília: INTERCOM, 2006.

BARACHO, A. F. O.; GRIPP, F. J.; LIMA, M. R. Os exergames e a educação física escolar na cultura digital. Revista Brasileira Ciência do Esporte, v. 34, n. 1, p.111-126, jan./mar. 2012.

BOCCHI, J. C. Corpo, subjetividade e o discurso da saúde: ensaio para profissionais de campo. Motricidades: Rev. SPQMH, v. 5, n. 1, p. 80-92, jan.-abr. 2021.

BRACHT, V. A constituição das teorias pedagógicas em Educação Física. Caderno Cedes, v. 19, n. 48, p. 69-88, ago. 1999.

CARR, N. A geração superficial: o que a internet está fazendo com os nossos cérebros. Rio de Janeiro: Agir, 2011.

CASTELLS, M. A sociedade em rede. 8. ed. São Paulo: Paz e Terra, 1999.

CORRÊA, E. A.; HUNGER, D. Educação Física e tecnologia: o processo de "tecnização" educacional. Curitiba: Appris, 2020a.

CORRÊA, E. A.; HUNGER, D. Reflexões do processo de "tecnização" das tecnologias em Educação Física. In: TESTA JUNIOR, A. (org.). Conversas sobre a formação profissional em educação física. Curitiba: CRV, 2020b. p. 13-32.

DONATI, L. P. Computadores vestíveis: convivência de diferentes espacialidades. Conexão Comunicação e Cultura (UCS), v. 3, n. 6, p. 93-102, 2004.

ELIAS, N. Escritos e ensaios: estado, processo, opinião pública. Rio de Janeiro: Jorge Zahar, 2006.

ELIAS, N. O processo civilizador: formação do Estado e Civilização. Rio de Janeiro, Jorge Zahar, 1993. (v. 2).

ELIAS, N. Introdução à sociologia. São Paulo: Martins Fontes, 1980.

FERREIRA, G. R. Educação e tecnologias: experiências, desafios e perspectivas 2. Ponta Grossa: Atena Editora, 2019. (recurso eletrônico).

GAMA, M. A ideologia do consumo na moda: uma visão diacrónica. Comunicação e Sociedade, v. 24, p. 210-220, 2013.

GARCIA, W. Corpo e tecnologia na sala de aula: estudos contemporâneos. Comunicação \& Educação, v. 15 , n. 3, p. 39-46, set/dez 2010.

GAYA, A. Será o corpo humano obsoleto? Sociologias, v. 7, n. 13, p. 324-337, jan./jun. 2005.

GONÇALVES JUNIOR, L. Dialogando sobre a capoeira: possibilidades de intervenção a partir da motricidade humana. Motriz, v. 15, n. 3, p. 700-707, 2009.

HARARI, Y. N. Homo Deus - uma breve história do amanhã. Companhia das Letras, 2016. 
HUNGER, D.; SOUZA NETO, S. PEREIRA, J. M.; FRANCO, F. C.; ROSSI, F. Formação acadêmica em Educação Física: "Corpos” (Docente e Discente) de conhecimentos fragmentados... Motriz, v. 15, n. 1, p. 79-91, jan./mar. 2009.

KENSKI, V. M. Impacto da mídia e das novas tecnologias de comunicação na educação física. Motriz, v. 1, n. 2, p. 129-133, dez. 1995.

LAZZArotti filho, A.; FIGUEIREDO, V. C. Editorial. Revista Pensar a Prática, v. 10, n. 2, 2007.

LE BRETON, D. A sociologia do corpo. 2. ed. Petrópolis: Vozes, 2007.

LÉVY, P. Cibercultura. São Paulo: Editora 34, 1999.

LÉVY, P. A inteligência coletiva - por uma antropologia do cyberespaço. São Paulo: Loyola, 1998.

LIMA, D. T.; HUNGER, D. Educação física escolar: crianças em movimento aprendendo criticamente o viver social. Curitiba: Appris, 2019.

LUCENA, R. F. Os Corpos de Elias: a concepção de corpo e educação a partir de três trabalhos de Norbert Elias. Educação \& Realidade, v. 42, n. 4, p. 1319-1332, out./dez. 2017.

MACHADO, A. M.; ZANETTI, M. C.; MOIOLI, A. O corpo, o desenvolvimento humano e as tecnologias. Motriz, v. 17, n .4, p. 728-737, out./dez. 2011.

MERLEAU-PONTY, M. Fenomenologia da percepção. 3. ed. São Paulo: Martins Fontes, 2006.

MOREIRA, W. W.; NÓBREGA, T. P. Fenomenologia, educação física, desporto e motricidade: convergências necessárias. Cronos, v. 9, n. 2, p. 349-360, jul./dez. 2008.

NÓBREGA, T. P. Corporeidade e educação física: do corpo-objeto ao corpo-sujeito. 2. ed. Natal: EDUFRN, 2005.

NÓBREGA, T. P.; ANDRIEU, B.; SILVA, L. A. N.; TORRES, L. T. Corpo, expressão e educação na natureza. Cadernos Cedes, v. 38, n. 104, p. 115-128, jan.-abr. 2018.

NÓVOA, A. Entrevista: nada será como antes. Revista Pátio, n. 12, nov. 2014.

NUNES, J. A. Como pensar a sociedade de conhecimento? Pro-Posições, v. 18, n. 1, p. 29-40, jan./abr. 2007.

OLIVEIRA, W. C.; DAMIANO, G. A.; PEREIRA, L. H. P. (orgs.). Corporeidade, educação e tecnologias: experiências, possibilidades e desafios. Jundiaí: Paco Editorial, 2015.

PAIVA, L. L.; GOELLNER, S. V. Reinventando a vida: um estudo qualitativo sobre os significados culturais atribuídos à reconstrução corporal de amputados mediante a protetização. Interface Comunicação, Saúde, Educação, v. 12, n. 26, p. 485-97, jul./set. 2008.

SCHWARTZ, G. M. Motricidade (pós)humana e a abordagem sobre o corpo na era da simulação. Motricidades: Rev. SPQMH, v. 3, n. 3, p. 213-221, set.- dez., 2019.

SELWYN, N. Educação e tecnologia: questões críticas. In: FERREIRA, G. M. S.; ROSADO, L. A. S.; CARVALHO, J. S. (org.). Educação e tecnologia: abordagens críticas. Rio de Janeiro: SESES, 2017. p. 85-102.

SERGIO, M. O desporto e a motricidade humana. Caderno de Educação Física e Esporte, v. 9, n. 16, p. 111-122, 1. sem. 2010.

SERGIO, M. Epistemologia da motricidade humana. Lisboa: Edições FMH, 1996. 
SOARES, C. L. Educação Física: raízes europeias e Brasil. 4. ed. Campinas: Autores Associados, 2007.

TARDIF, M. Saberes docentes e formação profissional. Petrópolis: Vozes, 2002.

UEBE, P.; DAMIANO, G. A. Interrelação: Corporeidade, Educação e Tecnologias. Revista ECOS Estudos Contemporâneos da Subjetividade, v. 6, n. 2, p. 319-323, 2015.

Recebido em: 04 ago. 2021.

Aprovado em: 07 set. 2021. 